\title{
The information society: Does it need the information professions?
}

\author{
John Feather
}

\begin{abstract}
A profession is constituted by a group of people with a shared body of knowledge and skills, based on formal training and well defined criteria. But the knowledge and skills which characterise the information profession, as defined by CILIP in the Body of Professional Knowledge and other documents, are no longer confined to those who describe themselves in this way, or feel any attachment to the information profession as traditionally defined. The paper discusses how this group do, can and should contribute to the so-called 'information society'. It challenges the idea that information society is in itself something new, and focuses more on the concept of the 'knowledge economy' in which information (and therefore information workers) have a key role. The challenge for the profession is to go beyond its own recognition of its knowledge, skills and insights, and to persuade others of the contribution it (and they) can make.
\end{abstract}

The CILIP Body of Professional Knowledge is unequivocal in its claims for the information professions:

The knowledge base defined in this paper has been adopted by CILIP (Chartered Institute of Library and Information Professionals) and establishes the unique knowledge, which distinguishes library and information professionals from professionals within other domains.

(CILIP, 2009b)

The document is wide-ranging and not lacking in depth. Yet this statement is not beyond question, especially when put in the context of another of CILIP's obita dicta, this time describing itself:

\section{John Feather}

John Feather is Professor of Library and Information Studies, Loughborough University, UK.

Email: j.p.feather@lboro.ac.uk 
CILIP: the Chartered Institute of Library and Information Professionals is the leading professional body for librarians, information specialists and knowledge managers.

(CILIP, 2009a)

The 'library and information professionals' referred to in the Body of Professional Knowledge are presumably to be equated with the 'librarians, information specialists and knowledge managers' in the strap line from the CILIP Website. Yet juxtaposing the 'professionals' and the 'specialists' in this way raises some interesting and perhaps disturbing questions about what constitutes this profession - or these professions!? - and what characterises their alleged uniqueness. In this paper, I want to address these questions, and in suggesting some of the ways in which they might be answered I shall also say something about the relationship between professional practice and research which will, I hope, be of interest to members of LIRG.

The concept of 'profession' is one which is carefully safeguarded, especially by those who consider themselves to belong to one. The Oxford English Dictionary (OED) defines it as

An occupation in which a professed knowledge of some subject, field, or science is applied; a vocation or career, especially one that involves prolonged training and a formal qualification

The essential elements are the application of knowledge, the prolonged training and the formal qualification. But there is a deeper layer of social meaning of which these cold words barely give a flavour. One of the OED's quotations hints at it:

Profession in our country is expressly that kind of business which deals primarily with men as men, and is thus distinguished from a Trade, which provides for the external wants or occasions of men.

This definition, from a work by the Christian Socialist F. D. Maurice, published in 1839 , does not evade the real issue, and nor does the OED's note on its own original definition in 1908:

Now usually applied to an occupation considered to be socially superior to a trade or handicraft; but formerly, and still in vulgar (or humorous) use, including these.

(s.n. II.b, headnote).

Here we have it. The professions - at least in England ('our country') - are more than mere occupations, and are certainly distinct from trade. Professions cater for people's 'inner needs', whether those needs are spiritual, physical or intellectual. Professional people will of course accept fees or salaries for their services, but they are not tradesmen for whom profit is the only motive. Only by way of a joke do we describe shopkeeping or plumbing as a profession.

New professions can of course evolve. Indeed throughout the $19^{\text {th }}$ century they proliferated. There was - and is - a peculiarly British way of signifying the point 
of transition from occupation to profession: the formation and public recognition of a professional body. A handful of such bodies have statutory authority to control entry and practice. Most do not, but through their royal charters or charitable objectives lay claim to regulating standards, which typically have some form of recognition in the wider community.

The British concept of Public, Statutory and Regulatory Bodies - PSRBs - is central to our understanding of what it means to qualify and practice as a member of a profession. In the non-statutory professions, however, these are merely the outward forms. The real defining factors of the profession are the knowledge and skills which practitioners possess and exercise. It is these that the CILIP Body of Professional Knowledge tried to capture. It is the expectation that they will be acquired through a formal programme of training and education and that there is a system of progressive attainment from entry level to professional leadership. But information work, like most of the non-statutory professions, is not and could never be a closed shop. It never has been and despite the proliferation of professional education in the second half of the $20^{\text {th }}$ century there is no sign of it becoming so. Indeed, we might argue that exactly the opposite trend can be seen.

There has been much talk in recent years of de-professionalisation, a phenomenon not unique to information work. We hear it from teachers concerned about the role of classroom assistants, we hear it from doctors as they watch the growth of the auxiliary professions in the healthcare sector, and we hear it from librarians who see people without formal qualifications take on posts which have traditionally been associated with qualified professionals. There are many alleged manifestations of this trend. As local authorities have combined formerly separate directorates into larger units, public libraries have found themselves with culture and leisure services, or perhaps with education, with the most senior officer having no background in library and information work. In many universities, the fashion - now beginning to reverse - for combining libraries with IT services and sometimes with other learning support services has had the same effect. Across the whole LIS sector we find staff who are undertaking tasks which fall well within CILIP's definition of professional work but neither are nor are required to be professionally qualified in the sense in which CILIP would understand it.

Some of these developments have of course been politically or financially driven. But, paradoxically, one of the most important factors has been the recognition of the increased importance of information, of the so-called information society.

The 'information society' has become a familiar phrase; it is even the title of a European Union programme and a portal on its Website (European Commission, 2009), not to mention of a journal and a number of books. But what do we mean by it? In practice, the EU associates it with the development and use of information and communications technologies. But the phrase is intended to imply far more than that. It means, in essence, a society in which knowledge and information are the building blocks of the social, political and economic structures through which it operates. The information society is the manifestation of the knowledge economy predicted by Machlup (Machlup, 1962) and analyzed by Porat (Porat, 1977) in the 1960s and 1970s; it is perhaps also the 'post-industrial society' of Daniel Bell (Bell, 1974) and others which was much discussed at about 
the same time. Broadly speaking, what these writers saw developing around them was an economy driven not by extraction and manufacturing but by the creation and interchange of knowledge and information. They predicted that the successful economies of the future would be those which fully exploited these drivers in the way that the successful economies of the $19^{\text {th }}$ and early $20^{\text {th }}$ centuries had been those which were based on activities such as coal mining and steel-making. In this new economy, all the key workers would be knowledge workers and their raw material would be information.

Forty years later, we can see that some of this has come to pass, although in the way of social prophecy it has not worked out exactly as it was expected to do. But the details are less important than the commonly held belief that information and information systems are now fundamental to the way we live and work. Yet that very statement should give us pause for thought. The key word is 'now', because it makes us ask when information was not fundamental. The transmission of knowledge, both explicit and tacit, is one of the defining characteristics of homo sapiens. The development of complex languages, and the much later development of the means of recording them in a way which can be transmitted over time and distance, has enabled us to become the dominant species on the planet. Being able to transmit knowledge and information means that we have been able to enhance it rather than merely accumulate it, as we add to the received knowledge store by creating new knowledge in each generation. That has been happening at least since the first writing systems were developed in the middle east about five thousand years ago. The invention of printing, first in east Asia in the $11^{\text {th }}$ century and then separately in western Europe in the mid- $15^{\text {th }}$ century, made the process more efficient. The knowledge store could more easily be encapsulated, preserved and transmitted and hence even further enhanced. It was a genuinely revolutionary technology, but it can be argued that it merely did better what had previously been done less well. And when we look at the history of the 500 years after Gutenberg, we see an increasing European, and especially western European, dominance over the whole world. The west's head start in developing an efficient communication technology was a significant factor in this development.

Computers were invented in a world which was already rich in knowledge and information and one in which the advanced economies were already moving away from the traditional industrial economic model towards one based on knowledge creation and exploitation. There is no doubt that more than any previous technology they have facilitated a quantum leap in our capacity to store, process and transmit information. This audience needs no reminding of that - those of us born in the age of the card index can never forget it! In the 1970s and 1980s as the scale of the transformation became clear, there were frequent and fevered discussions among people like us in which speaker after speaker foresaw a golden age of information and therefore for information professionals.

Up to a point that has happened. We have better access to more information than at any time in human history. And 'better' does not just mean less restricted or easier to find, it actually means qualitatively better than anything which went before. Simple examples will illustrate the point. How do I know what happened in the House of Commons yesterday? - I click. How do I find the time of my train? - I click. Moreover, with a comparatively inexpensive mobile device, I can 
do this pretty well whenever and wherever I like. This is indeed a golden age for information access. But is it one for information professionals?

The answer to that question is buried in how the information is actually organized and retrieved. Society has been transformed at every level and in almost every aspect. At the personal level, the information society means the capacity not merely to find out, but to do - to tax a car, to order one's shopping from a supermarket, to book a seat at the theatre. This is where the early prophets of the information age (a phrase in common use before it happened, and now largely fallen into desuetude) were not entirely accurate. Although they were remarkably prescient at the macro level, what was not envisaged was the pervasiveness of the communications dimension of digital technologies. Indeed, as late as the early 1990s, politicians, including some very IT-savvy politicians like Bill Clinton and $\mathrm{Al}$ Gore, were still talking in terms of wired networks using metaphors derived from road systems. The more or less simultaneous development of ubiquitous mobile technologies and the World Wide Web - both products of the mid-1990s actually completed the transformation. At the micro-level, access to information has become personal.

As information professionals, we understand that all of this is possible only because of the structure of the programs, systems and information resources which actually make the Web work, which sustain the networks, and which constitute individual Web sites and databases. But for all but a tiny handful of users this is as irrelevant as a knowledge of gearboxes is to the average car driver. The contribution of information professionals is at a different level. The development of the Web illustrates this perfectly. Berners-Lee set out to solve a very practical and urgent problem in information management. He turned to a proposal (hypertext) which had been developed at a conceptual level some twenty years earlier but never seriously pursued because the technology was inadequate, and added to it some design features which were made possible by the advances in interface design. Some of this work drew on the work of information researchers, and some on skills analogous to those of information professionals. If we look at Google or Microsoft today, we find them employing thousands of people, directly and indirectly, whose core skills are among those described in CILIP's Body of Professional Knowledge, as well as others whose research and development activities are focused on information storage, control, manipulation and retrieval. The public interface with information content is increasingly one which involves no immediate human contact, but specialist information work of the highest order is necessary for this to be achieved.

Of course, there are still information professionals whose work is built around working with clients. Some of them work in public-facing agencies like libraries, information service providers and advice bureaus. They are employed in the public and the private sectors, and they bring to their work the knowledge and understanding which enables them to help their clients. Why are they still needed? Partly no doubt because a professional can do the job more efficiently, but it would be a feeble justification for a profession if all it could do was save a little time and money on jobs which clients could do for themselves. The deeper answer lies in the ability to help the client to identify his or her real needs and then to satisfy them. And if that sounds remarkably like the work of a librarian, that is 
because it is. Libraries have many different roles; one of the most important in the information society is that they are a cost-effective way of providing access to the complex and high-level specialist information which all professionals need if they are to function in the knowledge economy, the information society.

All of which brings me back to the question in my sub-title, which was very carefully posed. It was 'Does it need the information professions', not information professionals. If the question were to have been framed in terms of 'professionals', the answer would be obvious enough - it is 'yes'. But framed as I have done, it is more difficult. We need to go back to the OED definition in which 'prolonged training and formal education' is merely an exemplification of an 'occupation in which a professed knowledge...is applied'.; this is the knowledge base which allegedly distinguishes information professionals from 'professionals in other domains' (CILIP, 2009b). While CILIP acknowledges an 'overlap with the knowledge bases of other professions, such as the British Computer Society, UK Council for Health Information Professionals and the Records Management Society', there is little in the Core Schema which is not generically applicable to many other professions. It would not be difficult to adapt many of the statements to apply to barristers, architects or nurses where there is a similar relationship between conceptual underpinning, a knowledge base and a pool of information applied for the benefit of clients. So the distinctiveness lies perhaps in what the Body of Professional Knowledge calls the 'Applications Environment'.

Here a somewhat stronger case be made. Some of the specifications are very specific indeed, relating for example to the need for a working knowledge of the relevant aspects of the law relating to information; ethical issues in relation to client confidentiality and other rights; and working within the governance framework of the organisation. The legal issues are particularly important, and becoming more so as questions about data protection, freedom of information and copyright occupy an increasingly prominent place in broader political agendas. In the explication of the Core Schema itself there is a statement about the role of the information professional in promoting information literacy, although little consideration of any obligation to help clients to maximise the benefits they can obtain from information - not least by showing them that it exists. And nowhere is anything said about how the profession is to promote its allegedly unique role in relation to all of those whose work is said to be in some way comparable.

This is not simply, or even primarily, intended as a critique of the Body of Professional Knowledge. The problem is more deeply rooted. If we look at the graduate-level workers who are professionally concerned with information, we find that only a small percentage are actually members of CILIP and even fewer actively engaged with it. University programmes which are unquestionably a preparation for information work - programmes in Information Management or Information Systems, for example - do not seek CILIP accreditation. Why not? Because they cannot see the benefit of doing so. And yet in many cases these programmes are highly regarded and their graduates find professional employment. We actually have very little understanding of public perceptions of information work. I do not mean by that another project to look at the public image of librarians - we have had more than enough of that. I mean a serious engagement with public perceptions of the information society, how it operates 
and who drives it. There is a research agenda here in which academic and practice-based researchers, like the members of LIRG, could very usefully work together. Yet any attempt to define that agenda in more detail will immediately show us that LIS specialists - whether academics or practitioners - are merely one of many groups of players and not perhaps the most important. To see some evidence for this, consider the pages on the EPSRC Website dealing with the programme called 'The Digital Economy', developed in conjunction with AHRC and ESRC, itself a measure of the range of disciplines and interests which it covers. (EPSRC, 2009). Nowhere in this programme is there any acknowledgement of the existence of an information profession. Here indeed is a research agenda, but it is one which crosses the boundaries of disciplines and professions to the point at which the boundaries no longer meaningfully exist. LIS researchers should be exploring those boundaries, looking beyond them and working with those who occupy adjacent territories whose own borders are equally ill-defined and porous.

So does the information society need the information profession? It certainly needs those who constitute it; it needs their insights, knowledge and skills. But we live, as I suggested earlier, in a deprofessionalising world. Indeed this is becoming one of the defining characteristics of the information society itself. We need to focus more on the application of our professed knowledge and rather less on the formal qualification. I know of course that CILIP has tried very hard to open its arms and it doors. But there is a long way to go if we are all to play the part that we could and should in the knowledge-based economy which is no longer a prophecy but a present reality. To achieve that we need a sounder research-driven evidence base for the significance and achievements of the information profession. That should be at the core of the practice-based research agenda for the future; LIRG, not least through its involvement in the newly formed Research Coalition (Kenna, 2008), has a critical role to play as a partner in its evolution and implementation. 


\section{References}

Bell, D. (1974) The coming of a post-industrial society: a venture in social forecasting. London: Heinemann.

CILIP (2009a) CILIP Website. URL: http://www.cilip.org.uk/default.cilip [accessed 16.07.09].

CILIP (2009b) Body of Professional Knowledge. URL:

http://www.cilip.org.uk/qualificationschartership/bpk [accessed 16.07.09].

EPSRC (2009) Digital Economy Programme. URL:

http://www.epsrc.ac.uk/ResearchFunding/Programmes/DE/default.htm [accessed 16.07.09].

European Commission (2009) Europe's information society. URL: http://ec.europa.eu/information_society/index_en.htm [accessed 16.07.09].

Kenna, S. (2008) Towards a coalition for research in library, archive and information science. Library and Information Research [online], 32(100). URL: http://www.lirg.org.uk/lir/ojs/index.php/lir/article/viewFile/68/87 [accessed 07.09.09].

Machlup, F. (1962) The production and distribution of knowledge in the United States. Princeton, NJ: Princeton University Press.

Porat, M. U. (1977) The information economy: definition and measurement. Washington, DC: United States Department of Commerce, Office of Telecommunications.

\section{Notes and Acknowledgement}

This is a slightly revised version of paper delivered after the LIRG Annual General Meeting at Umbrella 2009, University of Hertfordshire, 14 July 2009. I have chosen to retain the comparatively informal style of an oral presentation rather than try to turn this into an academic paper, which it was never intended to be. I am grateful to those who contributed to the discussion after the presentation, and to my colleague Professor Graham Matthews who read an earlier draft of the paper, for their comments, some of which they will see reflected in this version. 